\title{
Análise da conformação da trajetória tecnológica de máquinas e equipamentos agrícolas, a partir da perspectiva teórica neo-schumpeteriana
}

\author{
William Jose Borges ${ }^{1}$ \\ Silvio Antônio Ferraz Cario ${ }^{2}$ \\ Jose Paulo de Souza ${ }^{3}$
}

\begin{abstract}
Resumo: Neste trabalho, objetiva-se compreender como as empresas, pertencentes à indústria de máquinas e equipamentos agrícolas no Brasil, respondem aos estímulos que a dinâmica inovativa exerce na conformação da trajetória tecnológica. Para cumprir com o objetivo proposto, esta pesquisa configura-se como teórica/empírica de base neo-schumpeteriana, de natureza qualitativa e do tipo descritiva. Como resultado, a forma que as empresas encontraram para lidar com isso foi apropriar-se dos avanços tecnológicos existentes, gerir mecanismos de aprendizado, realizar esforços de capacitação inovativos e estratégias empresariais que contribuam para o desenvolvimento de máquinas e equipamentos agrícolas automotrizes.
\end{abstract}

Palavras-chave: Inovação. Trajetória Tecnológica. Indústria de Máquinas e Equipamentos Agrícolas.

Analysis of conformation of the trajectory of machinery technology and equipment agricultural from the perspective theoretical neo-schumpeterian

\begin{abstract}
This study aimed to understand how companies of agricultural machinery and equipment industry in Brazil, respond to the stimuli that the innovative dynamic carry out to the construction of technological trajectories. To comply with the proposed objective, this research is configured as a theoretical / empirical based
\end{abstract}

\footnotetext{
${ }^{1}$ Doutor, Professor de Administração do Instituto Federal de Santa Catarina (IFSC) em Jaraguá do Sul (SC) Brasil. E-mail: williamborges_88@hotmail.com

${ }^{2}$ Doutor, Professor do Curso de Graduação e Pós-Graduação em Economia e Administração da Universidade Federal de Santa Catarina (UFSC), Florianópolis - Brasil. E-mail: fecario@yahoo.com.br

3 Doutor, Professor do Curso de Graduação e Pós-Gradução em Administração da Universidade Estadual de Maringá (UEM), Maringá - Brasil. E-mail: jpsouza@uem.br
} 
neo-schumpeterian, qualitative and descriptive. As a result, the way that companies are to deal with it was to appropriate the existing technological advances, manage learning mechanisms, conduct innovative qualification efforts and business strategies that to contribute to the development of agricultural machinery and equipment.

Keywords: Innovation. Technological trajectory. Industry of agricultural machinery and equipment.

Classificação JEL: $\mathrm{O}_{3} 0$.

\section{Introdução}

Tomando-se como referência os delineamentos teóricos da abordagem neoschumpeteriana, esta pesquisa volta-se para a análise e compreensão da dinâmica industrial, que conforma a trajetória tecnológica presente nas empresas que participam do setor de máquinas e equipamentos agrícolas no Brasil. Ao se considerar esse ramo de atividades, é possível notar que, historicamente, muitas instituições, tais como associações, institutos de pesquisa e o próprio conjunto de empresas do setor, têm trabalhado a favor do desenvolvimento de novas possibilidades de trabalho. Esse processo, que se estende, no Brasil, desde meados da década de 40 do século XX, tem ganhado forças, nos últimos anos, perfazendo um grande portfólio de produtos e serviços que, no médio prazo, são capazes de desenvolver as cadeias produtivas, fornecendo produtos e serviços de alta qualidade.

No Brasil, a expansão do agronegócio, que representou 21,34\% do PIB, em 2014 (MAPA, 2016), foi marcada por uma onda de investimentos, pós II Guerra Mundial, e por políticas públicas que alavancaram as compras e a subsequente produção das empresas que comercializavam máquinas e equipamentos. De acordo com Castilhos et al (2013), os dois principais exemplos dessas políticas foram o Plano Nacional da Indústria de Tratores Agrícolas, contido no Plano de Metas do governo de Juscelino Kubitscheck e, anos depois, o programa de Modernização da Frota de Tratores Agrícolas e Implementos Associados e Colheitadeiras, o conhecido MODERFROTA. Esse último programa foi lançado no início dos anos 2000, pelo BNDES, e impulsionou o agronegócio com novos incentivos no ramo (ANFAVEA, 2013b, 2015).

No que tange ao setor de Máquinas e Equipamentos agrícolas, sabe-se que a tecnologia evoluiu de uma forma acelerada, passando de um cenário em que havia predominância de tração animal para a fabricação de equipamentos de base 
eletromecânica. Compreender como as empresas comportaram-se frente às mudanças técnicas que ocorreram ao longo da trajetória tecnológica demonstra ser uma frente de pesquisa compatível com o progresso da ciência. Entende-se, portanto, que os progressos técnicos (mudanças técnicas nas máquinas, equipamentos, implementos agrícolas, entre outros baseados em estímulos ao processo inovativo) contribuíram para a criação de novos produtos e serviços, gerando máquinas e equipamentos de maior qualidade, melhor utilização do espaço produtivo, novos relacionamentos homem/máquina, aumento da eficiência, entre outros recursos na agricultura.

Assim, este trabalho tem como objetivo compreender como as empresas, pertencentes à indústria de máquinas e equipamentos agrícolas no Brasil, respondem aos estímulos que a dinâmica inovativa exerce na conformação da trajetória tecnológica. Nesse sentido, para explicar esse movimento de mudança, utiliza-se a abordagem de cunho neo-schumpeteriano. Por meio desse tratamento, interpreta-se a trajetória tecnológica presente no setor de máquinas e equipamentos agrícolas, considerando que a inovação faz parte de um conglomerado de descontinuidades e complexidades típicas do mercado, mas que, juntas, são aptas a interpretar a capacidade inovativa das empresas em questão.

\section{Tratamento teórico da abordagem neo-schumpeteriana}

Os autores neo-schumpeterianos avançaram no desenvolvimento do termo inovação, encarando-o como algo endógeno à dinâmica econômica. $\mathrm{O}$ entendimento geral é que a inovação caminha levando em consideração progressos técnicos, busca, seleção e rotinas, entre outros elementos dinâmicos da atividade inovativa. Dessa forma, acredita-se que os neo-schumpeterianos observam a tecnologia como algo inerente ao processo produtivo, não podendo ser entendida como um bem livre.

Dosi (1988), com o intuito de explicar a relação dessa tecnologia no âmbito da ciência, sinaliza que ela deva ser entendida como um complexo de conhecimentos práticos e teóricos, que englobam, além de equipamentos físicos, não apenas know-how, métodos e procedimentos, mas também experiências, de forma que a tecnologia inclui a percepção de um conjunto limitado de alternativas tecnológicas e de desenvolvimento. Com isso, os teóricos trabalham na perspectiva de compreender melhor as evoluções técnicas, sociais e econômicas, presentes no desenvolvimento produtivo das empresas em geral. Isso faz com que essa abordagem possibilite a interpretação dos fatos (ORSENIGO, 1995) com base na expertise dos agentes, bem como da sua capacidade dinâmica de mudar e competir.

Nesse contexto, os progressos são vistos como processos naturais da inovação, haja vista a constante necessidade de se adaptar às novas realidades 
ambientais e organizacionais. Do ponto de vista tecnológico, firma-se um paradigma, definido, segundo Freeman e Perez (1988), como sendo um conjunto de procedimentos que servem de base para nortear pesquisas tecnológicas, pelas quais poderão ser identificados os problemas, além de serem especificados os objetivos que podem ser perseguidos. Baseando-se nessa caracterização do paradigma, Dosi (1988) insere o contexto tecnológico pela vertente das necessidades, ou seja, pelos princípios científicos, necessários para executar uma determinada tarefa. O autor, com isso, desmembra o conceito e orienta a investigação para a resolução de um determinado problema que aguarda por solução. Cada solução constitui um ponto de avanço na linha do progresso técnico, formando, assim, a trajetória tecnológica. Para Dosi (2006), algumas características das trajetórias são definidas em forma de paradigmas, tais como: a existência de trajetórias genéricas ou mais circunscritas, assim como mais ou menos poderosas; o desenvolvimento capaz de incentivar ou coibir o avanço de novas tecnologias; as trajetórias tecnológicas sustentam algumas características cumulativas, dessa forma, os avanços inovativos associam-se com o posicionamento da firma diante da fronteira tecnológica; a incerteza e complexidade em trocar de uma trajetória para outra está associada ao quanto a trajetória andante tem valor quando comparada às demais tecnologias (FREEMAN; SOETE, 2008).

Esse envolvimento e essa influência que uma tecnologia tem com as demais tecnologias deriva das mudanças no paradigma técnico-econômico, que abrange inovações não apenas na tecnologia, mas também no tecido social e econômico no qual estão inseridas (TIGRE, 2006). Dessa forma, o paradigma sustentado por Freeman e Perez (1988) não é apenas técnico, visto que requer mudanças institucionais e organizacionais para se firmar. Nesse sentido, portanto, uma mudança de paradigma envolve grandes ramificações econômicas. Dosi (2006) reforça a ideia defendendo que, na abordagem de trajetórias, o avanço tecnológico é internalizado, diferenciando-se com base em tendências tecnológicas desenvolvidas pelas empresas. Esses movimentos estabelecem uma dinâmica singular no que diz respeito à atuação e ao enquadramento das respostas ao meio ambiente, gerando rotinas que podem induzir a mudança no processo inovativo ao aproveitar uma oportunidade.

Essas rotinas foram estudadas por Nelson e Winter (2005), dois importantes autores para a teoria evolucionista, apresentando conceitos e alinhamento entre o núcleo teórico evolucionário e as mudanças técnicas, que podem transformar a estrutura econômica. Esses autores delimitam o conceito de rotina como uma atividade verificada no dia a dia das pessoas inseridas na comunidade e que direcionam o percurso das organizações. Por outro lado, vale frisar que os direcionamentos das ações individuais e coletivas são reflexo direto do aprendizado e da experiência de cada entidade pensante (LEMOS, 1999), ou seja, 
de cada indivíduo. Dentre as características observadas por Nelson e Winter (2005), a respeito das rotinas, estão: (1) a rotina como memória da organização, isto é, a rotinização das atividades gera um agrupamento de conhecimentos específicos; (2) a rotina como trégua, que é a combinação do mecanismo de imposição de regras e de outras motivações, que proporcionam satisfação ao quadro de colaboradores em cumprir suas funções dentro da própria rotina organizacional; (3) a rotina como meta: controle, cópia e imitação, em que as empresas são postas a definir novas rotinas e, para isso, utilizam-se da imitação de rotinas de outras empresas; (4) as rotinas atreladas às habilidades, em que a compreensão das habilidades individuais informa a compreensão do comportamento da organização; (5) a rotina ótima ou rotinas de otimização, de forma que o conhecimento das rotinas é o ponto-chave da compreensão do comportamento da organização como um todo; (6) as rotinas heurísticas ou de inovação, que acarretam mudanças nas rotinas; (7) as rotinas como genes, em que as informações mais importantes de coordenação são mantidas no funcionamento das rotinas.

Com base nessa compreensão das rotinas, entende-se que o acúmulo de conhecimento, bem como a repetição das atividades contribuem para a solução de problemas do ambiente. Atuando nessa perspectiva, as novas soluções tecnológicas dependem do vigor dos agentes em procurar novos caminhos, considerando que cada empresa possui uma forma particular de buscar suas inovações, exercendo o seu aprendizado (ROSENBERG, 2006). O conceito de busca, nesse contexto, é trabalhado no sentido de delimitar as atividades de uma entidade que almeja mudanças no âmbito tecnológico, angariando possibilidades, tais como imitação, criação ou, até mesmo, adaptação. De acordo com Nelson e Winter (2005), a busca e seleção de novas oportunidades são aspectos simultâneos e interativos do processo evolucionário, gerando informações relevantes para a tomada de decisões.

A inovação, nesse sentido, não é fruto de um cálculo de otimização, mas, sim, do recurso a uma heurística, expressa por regras e procedimentos. Além disso, a heurística que caracteriza o processo de busca é fundamentada em conhecimentos humanos, limitados e acumulados ao longo do tempo (ALBAGLI; BRITO, 2003), os quais, embora não estejam voltados à obtenção de soluções ótimas, permitem gerar inovações por meio da adoção de estratégias inovativas (FREEMAN, 1982). Sabendo das limitações e influências das rotinas no processo das empresas, tem-se que o conhecimento, no contexto organizacional, também está sujeito a mudanças por escolha deliberada. Nesse sentido, sujeita-se a aumentar, quando os funcionários aprendem fazendo suas tarefas de forma mais eficiente; e a diminuir, quando esquecem detalhes das tarefas que não fizeram em tempos recentes. O estudo de Nelson e Winter (2005) contempla os tipos de conhecimento devido ao impacto que a sua apropriação causa nas organizações, 
aprimorando habilidades e desenvolvendo novos recursos. A constituição de um conjunto de rotinas (MILAGRES, 2011) na empresa gera uma operacionalidade condizente com os afazeres imediatos, contribuindo com a inovação (PENTLAND, et.al, 2012).

De acordo com Lemos (1999), o processo de geração de conhecimento e inovação individualiza o desenvolvimento de capacidades, tanto tecnológicas quanto científicas e organizacionais. O aprendizado é, portanto, a exploração de oportunidades tecnológicas, que melhoram os mecanismos de busca e habilitam a criação de novos produtos. Acredita-se que as empresas podem aprender por meio de conhecimentos universais, conhecimentos específicos, conhecimentos públicos e conhecimentos privados. Assim, retomando o tema acerca do caráter cumulativo do conhecimento, Malerba (1992) aprofunda a discussão e salienta o termo apropriabilidade, tornando possível o tratamento da dependência que as empresas apresentam com relação ao conhecimento dos seus membros.

Com base nessas constatações, a procura pelo aprendizado (NONAKA; TAKEUCHI, 1997; LUNDVALL, 2004) e acúmulo de conhecimento é entendido como parte constituinte do comportamento das empresas, podendo ser denominado como uma espécie de rotina. Malerba (1992) resgata seis tipos de aprendizados condizentes com o processo preparatório: learning by doing, learning by using, learning by interacting, learning from advances in science and technology, learning from inter-industry, e learning by searching. Todas essas formas de aprendizado constituem uma rotina destinada a preparar as empresas para o futuro, sendo importante atualizar as características de um produto em sua trajetória. As características dessa atualização estão correlacionadas às capacidades organizacional e tecnológica, desenvolvidas no decorrer dos anos, haja vista que as suas competências foram lapidadas e treinadas para identificar as oportunidades e desenvolver as atividades inovativas, correspondentes ao padrão setorial vivenciado pela empresa (PAVITT, 1984; CASTELLACCI, 2008). Nessa perspectiva, Nelson e Winter (2005) apontam que esses regimes devem ser interpretados como a fronteira das aptidões realizáveis, com base nas limitações econômicas, físicas, biológicas, etc., dentro de uma maneira, genericamente, definida de fazer as coisas. Assim, reforça-se a ideia de que o regime tecnológico está ligado à capacidade de as organizações aproveitarem a tecnologia disponível, a fim de buscarem e selecionarem inovações.

\section{Metodologia}

Para analisar as respostas inovativas das empresas de máquinas e equipamentos agrícolas, com base na conformação da trajetória tecnológica, optou-se, neste estudo, por averiguar teorias que contemplem a concepção de 
tecnologia, seus significados, sua importância e trajetória. Nesse sentido, este trabalho contou, conforme já apresentado, com a elaboração de um referencial teórico acerca das teorias neo-schumpeterianas, que induzem à compreensão do emaranhado produtivo que circunda a produção de tratores médios, com rodas (100-199 cv), no Brasil. Além disso, diante do interesse em criar um sequenciamento de ideias coerentes, esta pesquisa contou com a formatação e recursos do software NVIVO $11^{4}$.

Os dados primários foram coletados visando atender o interesse em obter informações sobre a composição da estrutura social e produtiva do arranjo tecnológico durante todo o ano de 2014. Nesse sentido, no intuito de sustentar o corte de pesquisa em nível brasileiro, foram elaboradas entrevistas, voltadas para estudo nas empresas fabricantes de tratores no Brasil e registradas na Associação Nacional dos Fabricantes de Veículos Automotores - ANFAVEA (E1, E2, E3, E4 e $\left.\mathrm{E}_{5}\right)^{5}$, representando $88 \%$ de toda a produção nacional de tratores e pertencendo aos estados de São Paulo, Paraná e Rio Grande do Sul. Os entrevistados diretos, escolhidos por conveniência, formaram um grupo inicial de quinze pessoas (três pessoas para cada empresa), que foram submetidas a entrevistas semiestruturadas, destinadas aos gerentes de produção, gerentes de projetos, gerentes de qualidade, gerentes de inteligência de mercado, diretores e gerentes de concessionárias das empresas produtoras de máquinas e equipamentos agrícolas. Esse número poderia ser cada vez maior até que o pesquisador encontrasse uma saturação das respostas, de tal forma que o número de entrevistas iria aumentar até que se obtivessem dados consistentes para a apresentação no trabalho final e os novos dados não fornecessem informações complementares àquelas observadas.

Em seguida, um novo grupo de entrevistas foi formado, ainda para a coleta de dados primários, dessa vez, com entidades que incentivam o desenvolvimento do setor ou contribuem com ele, tais como Banco do Brasil, Banco Nacional de Desenvolvimento Econômico e Social - BNDES, Fornecedor em comum ${ }^{6}, \mathrm{CNH}$ Industrial, AGCO Corporation, Empresa Brasileira de Pesquisa Agropecuária EMBRAPA e ANFAVEA. Dessa forma, esse novo grupo de entrevistados principais foi formado de 16 entrevistas (uma a mais do que o planejado inicialmente). Acrescentou-se, ainda, à pesquisa mais sete entrevistas de instituições de apoio. Assim, o grupo formado, então, por 38 entrevistados, foi considerado consistente para o objetivo da presente pesquisa, sendo que em apenas um caso o pesquisador solicitou nova entrevista com E4 para aumentar a confiabilidade dos dados. Cabe

\footnotetext{
${ }^{4}$ NVivo é um software que suporta métodos qualitativos de pesquisa. Ele é projetado para organizar, analisar e encontrar informações em dados não estruturados ou qualitativos como: entrevistas, respostas abertas de pesquisa, artigos, mídia social e conteúdo web.

5 Empresas descaracterizadas a pedido dos entrevistados.

6 Nome oculto a pedido da empresa.
} 
salientar que, além das entrevistas presenciais, o pesquisador procurou manter contato com os entrevistados via e-mail para esclarecer dúvidas que surgiam no momento da análise.

Os dados secundários foram obtidos com base na análise de documentos e visitas a empresas: Associação Nacional dos Fabricantes de Veículos Automotores ANFAVEA; Documentos administrativos das empresas; Boletins informativos; Planos de governo; United States Department of Agriculture - USDA; Instituto Brasileiro de Geografia e Estatística - IBGE; Relação Anual de Informações Sociais RAIS; Food and Agriculture Organization of the United Nations - FAO; Ministério do Desenvolvimento, Indústria e Comércio Exterior - MDIC; Ministério da Agricultura, Pecuária e Abastecimento - MAPA; Associação Brasileira da Indústria Produtora e Exportadora de Carne Suína - ABIPECS; Banco Central do Brasil BACEN; Instituto Brasileiro de Geografia e Estatística - IBGE. Os relatórios institucionais desses órgãos foram utilizados para mapear, seguindo a literatura especializada, a divisão e organização do adensamento produtivo. Dito de outra forma, ao submeter esses relatórios aos padrões de organização, é possível verificar a competência de cada instituição em deliberar novas informações e, principalmente, novas capacitações de cunho tecnológico.

Dessa forma, mantendo o objetivo geral do trabalho como referência para adaptar os passos de pesquisa, tem-se que este estudo é de natureza essencialmente qualitativa. Como complemento, a interpretação dos dados foi realizada com o auxílio da análise de conteúdo (BAUER; GASKEL, 2008). Além disso, esta pesquisa adapta-se melhor a uma indução descritiva, pois ajuda a descrever os fenômenos de uma determinada preposição. Malhotra (2001) defende que a abordagem descritiva é uma modalidade de pesquisa cuja característica fundamental é a descrição de algo, à medida que conhece e interpreta a sua realidade.

4. Caracterização e análise da trajetória tecnológica das empresas de máquinas e equipamentos agrícolas no Brasil

Dosi (2006, p. 42) defende que a trajetória tecnológica pode ser compreendida como "o padrão da atividade normal de resolução do problema (isto é, do progresso), com base num paradigma tecnológico”. Isso quer dizer que as empresas procuram atualizar o seu produto de acordo com os problemas novos que surgem, com as novas tecnologias que são desenvolvidas, com o acúmulo de conhecimento que elas obtiveram ao operarem no mercado, entre outras fontes de mudanças. Nesse sentido, ao avaliar os avanços tecnológicos do setor de máquinas e equipamentos 
agrícolas, observa-se que as empresas têm mudado o seu produto anualmente, criando tecnologias para uso nos tratores médios com rodas.

Essa perspectiva dinâmica do comportamento das montadoras, com base nos movimentos de inserção tecnológica, sinaliza uma flexibilidade para o futuro da trajetória tecnológica, ao reajustarem o trajeto para se adequarem a um novo contexto econômico, político, social, organizacional ou tecnológico. Em alguns casos, como relatado por $\mathrm{E}_{1} \mathrm{~F}_{3}, \mathrm{E}_{3} \mathrm{~F}_{2}$ e $\mathrm{E}_{4} \mathrm{~F}_{4}$, os tratores recebem tecnologias que não estavam previstas para o modelo, mas que, por facilidades, dificuldades e análises de mercado, os gestores resolvem alterar o trajeto das inovações. Dessa forma, observa-se que a tecnologia, os comportamentos do mercado, os conhecimentos internos e políticas públicas importam para a trajetória tecnológica. Observou-se que o discurso dos representantes das empresas é de que o conhecimento gerado nelas gera um padrão cumulativo ao longo dos anos e que, de acordo com o tratamento dado a esse aprendizado, os processos de busca e seleção tornam-se mais rápidos e dinâmicos.

Os entrevistados posicionaram-se de forma homogênea ao serem questionados sobre esses assuntos, facilitando a identificação dos padrões encontrados no setor. Um ponto bastante difundido nas argumentações foi que o setor nunca avançou tanto quanto nos últimos 20 anos. $\mathrm{O}$ pressuposto por trás da análise das trajetórias tecnológicas é que essas mudanças são capazes de influenciar na dinâmica industrial deste setor. A partir desses avanços, a trajetória tecnológica, bem como o comportamento das empresas do setor de máquinas e equipamentos agrícolas, altera-se também. Seguindo os ensinamentos de Dosi (1988), é possível constatar que os rumos da trajetória tecnológica são, fortemente, influenciados por fatores endógenos. Isso quer dizer que, para compreender como os agentes respondem aos estímulos tecnológicos do setor, é preciso identificar, em primeira mão, quais mudanças tecnológicas foram importantes para o setor e como elas foram apropriadas pelas empresas de máquinas e equipamentos agrícolas. A Figura 1, na sequência, ilustra as principais mudanças tecnológicas, a partir de seus eixos temáticos, considerando o momento em que os entrevistados se referiram à mudança técnica no tempo.

Assim, com base na análise de conteúdo, foi possível identificar sete conjuntos de mudanças presentes na trajetória tecnológica dos tratores médios de rodas: motorização e transmissão; pneu e freio; força hidráulica e elétrica; segurança; conforto do operador; agricultura de precisão; e outras mudanças. Cabe 
salientar que os conjuntos de mudanças foram gerados com base na análise de conteúdo dos entrevistados, não representando todas as mudanças pelas quais os tratores passaram, tampouco todas as inovações procuradas e desejadas pelas empresas. Trata-se de um agrupamento de ideias que representam um vetor de mudanças internas, que acaba impulsionando a dinâmica inovativa das empresas analisadas.

Figura 1: Principais mudanças técnicas presentes na trajetória tecnológica dos tratores do Brasil, 19602015.

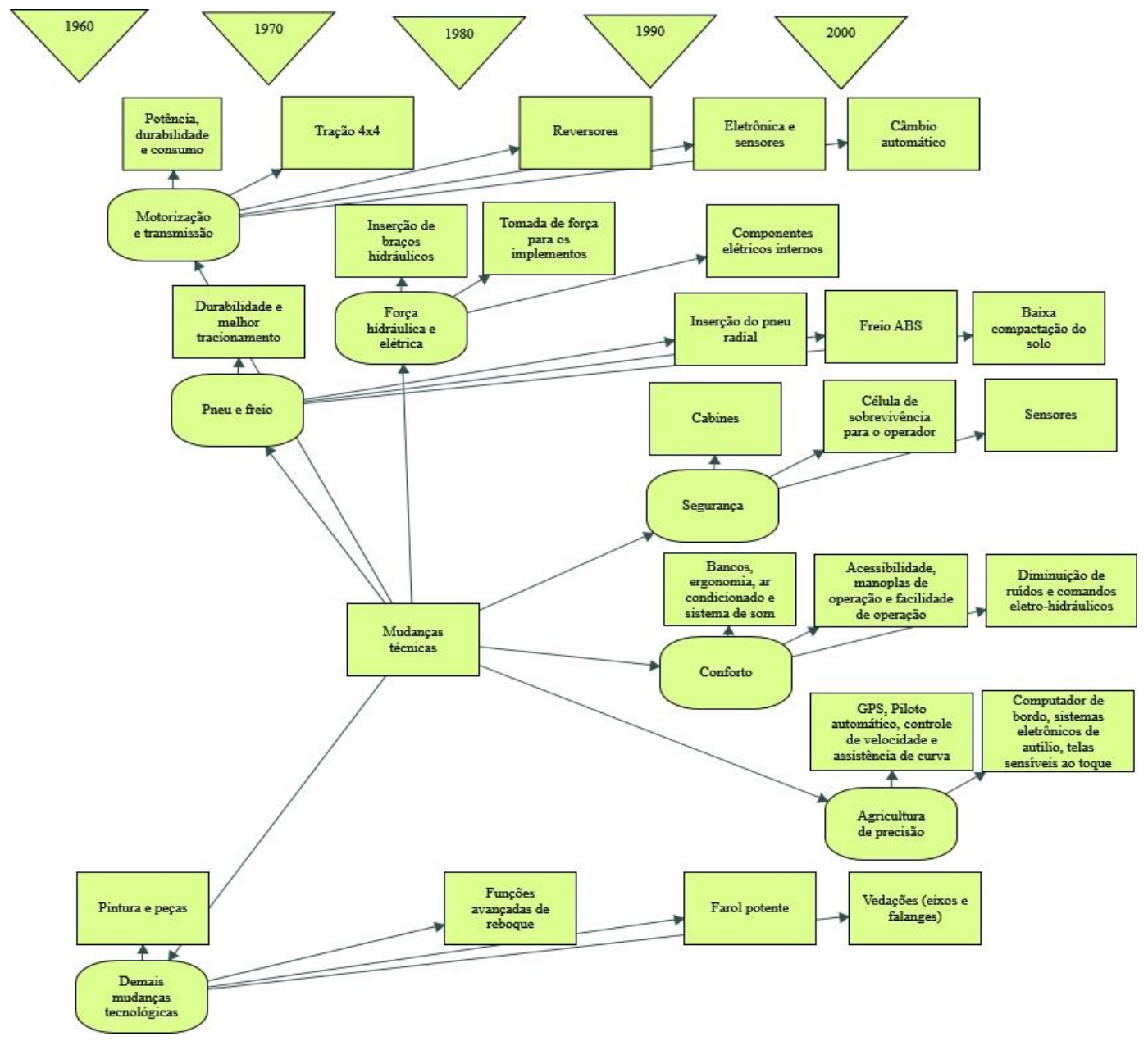

Fonte: Elaborada pelo autor, com base nos dados primários da pesquisa. 
Para estabelecer essa configuração da trajetória tecnológica, bem como o comportamento das empresas do setor, é preciso observar o processo sob o ponto de vista do aprendizado, dos esforços inovativos e das estratégias empresariais adotadas.

\subsection{Aprendizado e conhecimento no contexto inovativo}

De acordo com Lemos (1999), a própria empresa cria condições para que o aprendizado ocorra, fixando e acumulando o conhecimento internamente. Para que isso se materialize, as empresas aprimoram suas ações internas, visando captar informações e propor alterações relevantes, que podem ser vistas no design do produto, na sua força, produtividade e usabilidade no campo. Vale salientar que a procura por essas mudanças sempre esteve fortemente respaldada nas necessidades do campo e na apropriação de conhecimentos no cenário tecnológico mundial. Dessa forma, as empresas desenvolveram ferramentas para facilitar o aprendizado, bem como ferramentas para reter o conhecimento.

Conforme identificado na literatura, por meio dos trabalhos de Nonaka e Takeuchi (1997), Malerba (1992) e Lundvall (2004), o processo de aprendizado nas empresas pode ser desenvolvido por meio de seis grandes processos, conhecidos como learning by doing, learning by using, learning by interacting, learning from advances in science and technology, learning from inter-industry e learning by searching. Os autores defendem que essas formas de aprendizado constituem uma rotina destinada a preparar as empresas para o futuro. De fato, os entrevistados reafirmaram esse posicionamento, sinalizando que a busca pelo conhecimento ocorre em múltiplas formas, nas empresas. $\mathrm{O}$ entrevistado $\mathrm{E}_{5} \mathrm{~F}_{3}$ relata: "Aqui, nós temos sistemas de gestão da qualidade que a melhoria contínua é adotada. Nesse sistema, todos os funcionários passam por treinamentos contínuos na fábrica, mas também conseguem desenvolver melhorias sozinhos [...]”. E complementa dizendo que o processo produtivo é aberto para possíveis modificações em sua estrutura, passando por uma análise interna até que a mudança seja aprovada. Por meio da análise desse conteúdo, é possível identificar que a estrutura do conhecimento que está sendo utilizada por esses funcionários que inovam é a do learning by doing, pois utilizam o próprio contexto produtivo para gerarem melhorias ao adotarem o conhecimento como fonte de mudanças.

Rosenberg (2006) destaca que o funcionário utiliza essa metodologia quando o conhecimento tácito do processo e/ou da operação está bem aprimorado, de modo que o envolvido no aprendizado desfrute de novas habilidades de produção, realizando inovações incrementais. De acordo com o observado nas entrevistas realizadas, o learning by using e o learning by searching são formas importantes de se obter conhecimento pelas empresas. Isso porque essas modalidades permitem 
que as instituições continuem aprendendo, mesmo depois que o produto está no mercado consumidor. Com base nesses relacionamentos, os atributos tangíveis e intangíveis dos tratores vão sendo aprimorados em processos de qualidade. Conforme salientado por Rosenberg (2006), esse tipo de aprendizado é importante também no que se refere aos bens de capital, pois, frequentemente, as características de desempenho de um bem de capital durável não podem ser entendidas antes que se tenha uma prolongada experiência com ele. Com isso, as fabricantes instalaram, na grande maioria dos estados brasileiros, concessionárias que, além de prestarem serviços técnicos, coletam informações de experiências de clientes.

Essa relação de aprendizado entre fabricante e usuário também é vista como um processo facilitador da inovação, aproximando as múltiplas formas de aprendizado existentes. A empresa participa desse processo, aportando conhecimentos técnicos sobre o produto e o usuário, disponibilizando experiências com o uso do equipamento. Dessa forma, o intercâmbio de dados induz um processo de atualização do referido equipamento, na medida em que apresenta suas necessidades práticas, suas dificuldades de manejo e intenções futuras com a utilização do equipamento em suas culturas produtivas.

Essa modalidade de aprendizado está muito próxima de outra modalidade, também utilizada internamente, que é o learning by interacting, em que a empresa funde o aprendizado que ocorre em suas próprias instalações, com o aprendizado que ocorre com seus fornecedores e demais elementos de ligação. Isso ocorre porque, muitas vezes, os próprios fornecedores estimulam as inovações internamente, seja por históricos de problemas passados, seja por angariar formas de obterem vantagens competitivas. De uma forma ou de outra, a interação entre as instâncias produtivas privilegia a troca de informações qualitativas entre os usuários, as quais representam grande potencial de mudanças.

$\mathrm{Na}$ análise dos dados da pesquisa foi possível identificar um relacionamento forte entre as fabricantes e os fornecedores de peças, do tipo learning from interindustry. Para os entrevistados, embora tenham relatado que trabalham sob a orientação de contratos de fornecimento de peças com agregação de tecnologias, observam que ainda há uma grande dificuldade em se formar bons fornecedores no Brasil em função da falta de infraestrutura e tecnologia para investirem no setor. A interação, nesse sentido, ocorre mediante um contrato, mas pode ser considerada uma troca de informações de qualidade, em que um agente aprende com o outro no relacionamento diário. Assim, os entrevistados $\mathrm{E}_{12} \mathrm{~F}_{2}$ e $\mathrm{E}_{5} \mathrm{~F}_{3}$ explicam que o relacionamento segue padrões de desenvolvimento entre as partes, de um lado, a fabricante desenvolve os modelos e adapta as tecnologias no projeto interno; de outro, os fornecedores desenvolvem os componentes a serem fornecidos com base em normas técnicas, usualmente, seguindo o Instituto Nacional de Metrologia, 
Qualidade e Tecnologia (INMETRO), e a Associação Brasileira de Normas Técnicas (ABNT). Com o tempo, as partes negociam melhorias, e/ou propõem avanços tecnológicos para atualizarem as peças comercializadas.

Observa-se que essas ideias inovadoras foram obtidas pelas empresas entrevistadas, não só internamente, como no caso anterior, mas também externamente. A caracterização desse tipo de aprendizado foi denominada por Malerba (1992) como learning from advances in science and technology. Ao se desenvolver essas ideias, entra em cena uma partilha de inovações e desenvolvimentos captados pelo próprio setor de máquinas e equipamentos agrícolas, mas capitaneados por outras indústrias no cenário técnico e tecnológico. Dentre as principais fontes para se obter o conhecimento via avanços da ciência e da tecnologia estão os departamentos de P\&D, as universidades e outras empresas. Essa aproximação de conhecimentos, pela análise do contexto em que é empregada, caracteriza-se mais como um learning from advances in science and technology que um learning from inter-industry spillovers, pois o relacionamento ocorre, naturalmente, na divulgação e no avanço tecnológico do setor, demonstrando que os avanços no setor de bens de capital requerem interação com outros conhecimentos. Todas as formas de aprendizado, vivenciadas pelas empresas e analisadas no presente trabalho, seguem uma mesma tendência que é a de criar e sustentar rotinas de busca e seleção de novas possibilidades internas.

Obviamente, a depender de suas estruturas, as empresas não esperam que outras empresas façam o trabalho de inovar para depois executarem uma simples adaptação, até porque essa demora em adotar as novas técnicas e tecnologias pode ser um fator de exclusão da companhia no mercado competitivo. O que se observou, portanto, foi um grande esforço de todas as empresas em gerarem inovações nos seus parques produtivos. De forma complementar à abordagem de Tigre (2006), a apropriação do conhecimento não está apenas nas novas oportunidades operacionais, mas também nas conquistas individuais e no alicerce do conhecimento como um todo. Isso quer dizer que a inovação está sendo aprimorada, desenvolvida, captada de forma cooperada nas instituições analisadas.

Por um lado, as empresas procuram desenvolver formas para gerarem aprendizado, por outro, as empresas encontram formas para reterem conhecimentos e acumularem experiências internas. Essa relação de influência direta entre o conhecimento e a trajetória tecnológica foi abordada, na década de 1980, nos trabalhos de Pavitt (1984), e ainda possui um caráter hodierno nas análises das empresas. Baseando-se nessa relação, entende-se que o desenvolvimento das tecnologias está intrinsecamente conectado com os processos de inovação e exploração do aprendizado nas empresas. A finalidade imediata, encontrada pelas empresas em análise, foi apropriar-se dessas múltiplas formas de 
aprendizado e conhecimento, por meio de rotinas de conhecimento, a fim de atenderem às expectativas dos clientes.

O estabelecimento da rotina (MILAGRES, 2011) como o cerne do processo de desenvolvimento promove uma aproximação com a teoria neo-schumpeteriana ao apontar a congruência entre os processos institucionais e históricos do ambiente. Dessa forma, observa-se que os esforços empresariais coadunam com uma dinâmica econômica, forjada ao longo dos anos, por meio de um processo de busca e seleção. A Figura 2 apresenta a forma como as empresas reagem frente aos desafios de desenvolverem um ambiente propício para o aprendizado, e demonstra os meios para acumularem o conhecimento.

Figura 2: Esforços empresariais para induzir o aprendizado e acumular conhecimento no processo de atualização do setor de máquinas e equipamentos agrícolas no Brasil, 2015.

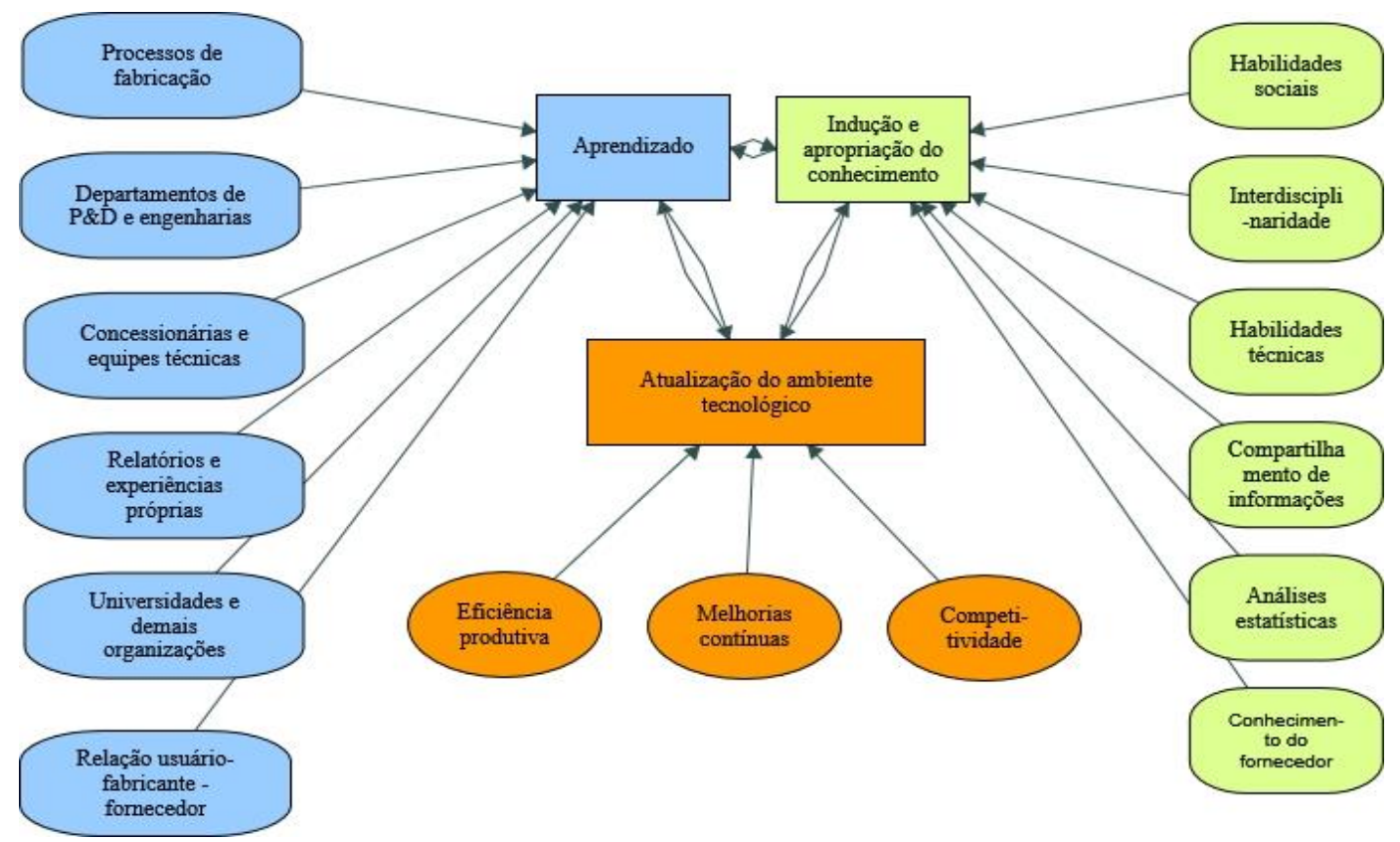

Fonte: Elaborada pelo autor, com base nos dados primários da pesquisa.

Assim, como demonstrado na Figura 2, os elementos que induzem o aprendizado e o conhecimento são dinâmicos e partem dos ambientes interno e externo. Isso quer dizer que as ferramentas de apropriação utilizadas precisam funcionar, absorvendo e desenvolvendo conteúdos para o trabalho interno. Dessa forma, os esforços empresariais, voltados para o aprendizado e conhecimento, habilitam a imagem de que a empresa necessita atualizar, constantemente, o seu 
ambiente tecnológico, pois é por meio dele que ela avançará na trajetória tecnológica. Esse avanço, como defendido por Dosi (2006), faz parte de um processo natural de resoluções de problemas e avanços técnicos, que vão ocorrendo no regime tecnológico.

Os esforços partem da intenção em atualizar o ambiente tecnológico para fornecer produtos inovativos ao mercado, pois, como se pode entender pelos relatos dos entrevistados, os clientes demandam por produtos com maiores adaptações para os trabalhos no campo. As formas de aprendizado expressas foram tabuladas, via software NVIVO, a fim de coletar a quantidade de citações que diziam respeito às formas de se obter aprendizado nas empresas analisadas. Observa-se que as $\mathrm{E}_{4}$ e $\mathrm{E}_{5}$ apresentaram um discurso voltado ao aprendizado com o auxílio de novas tecnologias; a empresa E1 apresentou um comportamento intermediário; e as empresas E2 e E3 apresentaram um discurso mais voltado para formas de aprendizado com baixo envolvimento tecnológico.

O Gráfico 1 apresenta a distribuição dos dados coletados, levando em consideração a quantidade de citações que se relacionavam às formas de aprendizado. Observa-se, ainda, que todas as empresas apresentaram uma porcentagem alta de citações que diziam respeito ao learning from advances in Science and technology, demonstrando que o setor se aproxima de outras entidades que desenvolvem tecnologias, quando o assunto é aprender via avanços nas ciências e tecnologias. Parte desse movimento pode acontecer em função das atualizações setoriais. Ao mesmo tempo em que as empresas estão procurando alternativas de atualização de seus equipamentos, outras organizações, associações e a própria cultura do campo estão procurando novas formas de responder aos problemas que surgem.

Gráfico 1: Distribuição de frequência na expressão das formas de aprendizado identificadas nas empresas do setor de máquinas e equipamentos agrícolas no Brasil, 2015.

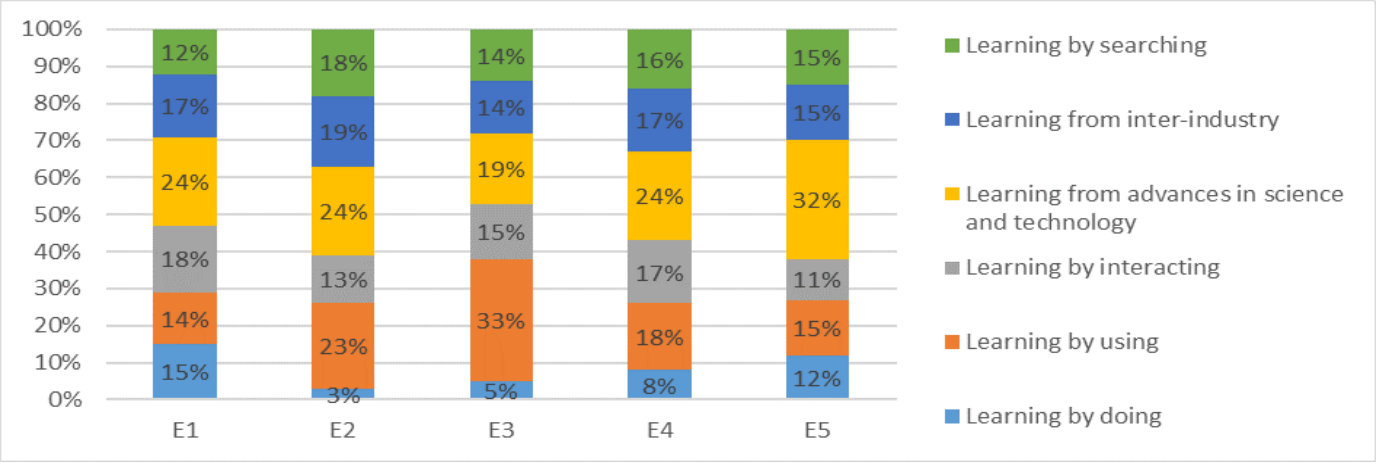

Fonte: Elaborado pelo autor, com base nos dados primários da pesquisa. 
As empresas, dessa forma, diferenciam-se em suas trajetórias tecnológicas (NELSON; WINTER, 2005). As empresas E4 e E5 desenvolvem tecnologias e criam suas próprias frentes de desenvolvimento (FREEMAN; SOETE, 2008), com base em suas visões fortemente voltadas para o aprendizado pelos avanços na ciência e tecnologia. As empresas E1, E2 e E3, dada suas escolhas, tendem a seguir as tendências de mercado, realizando pequenas adaptações nos produtos já existentes. Vale salientar que, muito embora tenham tomado caminhos distintos, cada empresa possui o seu mercado. A consequência observada é que, ao estarem a frente do desenvolvimento, as empresas tendem a se apropriar de tecnologias mais rapidamente, quando comparadas àquelas que não o fazem, culminando em maiores vendas no setor, o que é visto pelos entrevistados como uma recompensa pelos esforços inovativos.

A presença dos fornecedores na relação de aprendizado e conhecimento também deve ser levada em consideração, pois, por se tratar de uma atividade empresarial em que os relacionamentos são contratados, o fornecimento torna-se um elemento importante na transação. Percebe-se que, além de estimular o desenvolvimento de novas tecnologias internamente, os fornecedores também compartilham projetos e ideias com os seus contratantes. O interessante é que as duas empresas mais distantes, em termos de promoção da tecnologia (E1 e E5) manifestaram um alto grau de aprendizado na prática, porém, na primeira, isso foi observado via coleta de dados para a prospecção de mudanças e, na segunda, testando os resultados encontrados em P\&D.

Os esforços empresariais citados pelos entrevistados fazem parte do universo das empresas analisadas e representam as principais ações tomadas pelos diretores. Esses relacionamentos tornam-se complexos na medida em que a empresa precisa se relacionar com todos os agentes envolvidos. Essa estrutura representa a resposta dada pelas empresas, quanto aos esforços para estimularem o aprendizado e o conhecimento internamente. Obviamente, as ações em busca do aprendizado e do conhecimento tomaram esse corpo em função das explicações dadas em entrevista, podendo ser diferente em outro regime tecnológico.

\subsection{Esforços inovativos: buscas, rotinas e seleção}

É valido frisar que as empresas entrevistadas realizam, diariamente, esforços produtivos, de comercialização, de atendimento aos clientes, entre outros esforços. A presente pesquisa se voltou, contudo, para os esforços que induziam o desenvolvimento do trator médio com rodas, na perspectiva da inovação. Isso quer dizer que os esforços descritos, nesta seção, fazem parte de um grupo seleto de respostas que as empresas entrevistadas desenharam para atuar. Baseando-se nas 
respostas obtidas, constata-se a presença de impulsos empresariais que contribuem com a inovação dos produtos e, consequentemente, mudam o ambiente tecnológico. Esses impulsos tecnológicos fazem parte de um paradigma que as empresas compartilham, o qual, identificado, pode ser interpretado à luz de Freeman e Perez (1988), que defendiam que o paradigma técnico-econômico diz respeito à dimensão técnica, institucional e econômica.

Dessa forma, o conceito formado de paradigma para essas empresas representa o conjunto de conhecimentos com fundamentos técnicos, institucionais e econômicos que sustentam a busca de respostas para os questionamentos de ordem estratégica. Isso ocorre, pois, ao buscar respostas inovativas para o setor, as empresas deparam-se com o fato de que o paradigma não é algo estático, na medida em que o conhecimento é aplicado, novas realidades são construídas simultaneamente, transformando o processo e fortalecendo o caráter evolucionário (PENTLAND, et.al, 2012) do ambiente em que atuam.

A trajetória apresenta-se na medida em que as supostas oportunidades, identificadas nas buscas (CASTELACCI, 2008), são aproveitadas e desenvolvidas nos processos organizacionais, estabelecendo novos marcos institucionais e técnicos. A percepção é que, historicamente, esses processos internos de busca e seleção de oportunidades foram aprimorados e transformados em rotinas internas. Durante a coleta de dados, foi possível identificar, em todas as empresas, pessoas trabalhando sob a orientação funcional, em departamentos chamados de inteligência de mercado, $P \& D$ e departamento de engenharia. Obviamente, cada empresa nomeia os cargos de uma forma, mas, por meio das conversas in loco, constatou-se que existem pessoas ativando os processos de busca e seleção na forma de rotinas para proporem alterações no produto. Todas as empresas analisadas apresentam um posicionamento muito próximo daquilo que Orsenigo (1995) relatou em seu trabalho, dizendo que as empresas, inseridas em um contexto inovativo baixo, podem escalonar as suas atividades de inovação de acordo com a velocidade do setor.

No entanto, é valido frisar que, ao gerar novos conhecimentos, as organizações estabelecem um novo conjunto de possibilidades de uso tecnológico, haja vista que a capacidade de transformação foi alterada. O curioso é que isso não é garantia de uso efetivo das novas tecnologias, pois isso dependerá dos demais conhecimentos incorporados pela organização, bem como a expertise da entidade em visualizar uma oportunidade em seu ambiente de atuação e tomar a decisão de explorá-la.

Dessa forma, observou-se que as empresas E1, E4 e $E_{5}$ apresentam um posicionamento mais ativo em relação à inovação; por outro lado, as empresas E2 e E3 demonstraram um comportamento mais passivo frente ao mercado de máquinas e equipamentos. Isso não quer dizer que as três empresas mais 
dinâmicas possuam operações de $\mathrm{P} \& \mathrm{D}$ avançadas, no Brasil, muito pelo contrário, se comparadas aos outros centros do mundo, tais como EUA e França, os centros brasileiros realizam, fortemente, inovações adaptativas. Para isso ocorrer, nesse processamento, as empresas têm sete rotinas a realizar: visitas técnicas; relacionamento com concessionárias; relacionamento com fornecedores; projetos internos guiados pelos funcionários; mapeamento de leis e programas do governo; pesquisas em parcerias e laboratórios de testes; e crédito.

A primeira rotina desenvolvida pelas empresas é destinar um conjunto de funcionários para realizarem, constantemente, visitas técnicas, identificadas em dois momentos. A primeira modalidade de visita técnica é aquela realizada aos produtores rurais, a fim de identificarem se o produto está adequado ao uso rural. A segunda modalidade de visita técnica ocorre em feiras rurais, onde as fabricantes montam seus stands e recebem os produtores rurais para conversar, aprender e negociar.

Em complemento, o avanço guiado pelo relacionamento com a concessionária, considerado como a segunda rotina, ocorre em função da proximidade que os concessionários mantêm com os seus clientes. Para vender um trator, a concessionária precisa estar ciente da cultura, do manejo, da periodicidade das vendas, das inovações na agricultura, da usabilidade do usuário, dos problemas apresentados, da capacidade financeira, entre outras informações. Para operacionalizar essa conexão, as fabricantes utilizam telefonemas, e-mails e plataformas digitais, para que as concessionárias incluam modificações técnicas nos tratores que poderiam fazer diferença em sua região. Em seguida, essas possibilidades são organizadas por eixos temáticos e encaminhadas para os departamentos capazes de induzir a inovação internamente, que, nesse caso, seriam os departamentos de inteligência de mercado ou o de engenharia.

A terceira rotina, relacionamento com fornecedor, também ocorre, frequentemente, nas empresas, pois muitas mudanças técnicas, identificadas na fábrica, podem ser realizadas pelos fornecedores, haja vista a grande quantidade de peças compradas pelas empresas analisadas. Em continuidade, os projetos internos guiados pelos próprios funcionários, identificados como a quarta rotina, seguem uma lógica de aproveitar os profissionais capazes de inovar, aplicando os conhecimentos técnicos e tecnológicos. Teoricamente, sabe-se que cada setor apresenta uma velocidade distinta de inovação, sendo necessário, de acordo com Orsenigo (1995), realizar ações de interpretação das pressões presentes no campo. Seguindo a definição de Dosi (2006), a tecnologia também é entendida como um conjunto de parcelas de conhecimento, métodos, procedimentos e outros métodos de trabalho.

A quinta rotina, mapeamento de leis e programas do governo, demonstrou ser uma rotina recorrente nas empresas analisadas, pois o governo oferece 
subsídios e incentivos no mercado e, para aproveitar esses programas, as fabricantes precisam alinhar os produtos que serão ofertados. Dessa forma, as empresas sinalizaram que possuem pessoas especializadas em mapear as oportunidades do mercado, pois, quando o governo cria um edital específico, como é o caso do "Trator Solidário", ele induz uma demanda de mercado que irá procurar por tratores de $55 \mathrm{CV}$ e $75 \mathrm{CV}$ de potência, por preços que vão de $\mathrm{R} \$$ 48.500,00 a R $62.400,00$, respectivamente. Isso também ocorre com outros editais e programas lançados pelo governo.

A sexta rotina identificada nessa modalidade de esforço inovativo foi o trabalho diário nos laboratórios de testes. Os esforços acontecem na medida em que avaliam os tratores no laboratório, simulando a rotina de trabalho que os equipamentos teriam no trabalho diário do campo. Os entrevistados frisaram a importância dessa etapa, pois é nela que são identificados os maiores avanços em termos de capacidade produtiva e robustez do equipamento.

No que diz respeito à sétima rotina, captação e utilização do crédito, como indutora da inovação, os entrevistados salientaram alguns processos que recebem recursos diretamente e com mais frequência nas empresas. Isso quer dizer que, por serem recursos próprios, as empresas alocam em toda a fábrica, mas, para os efeitos dessa pesquisa, foram considerados somente os recursos voltados para o desenvolvimento da trajetória tecnológica dos tratores. Assim, dentre os ambientes citados pelos entrevistados, destacam-se as plantas, os investimentos em pessoal, os investimentos em maquinários e P\&D.

Essa estratégia das empresas em investir em $\mathrm{P} \& \mathrm{D}$ tem sido recursiva no setor de máquinas e equipamentos agrícolas. Algumas empresas, tais como as E1, E4 e $E_{5}$, relataram que procuram fontes alternativas de financiamentos para realizarem P\&D. Como consequência, além de realizarem investimentos, foram observados processos de catching up. Constatou-se que, por estarem próximas do setor automobilístico, muitas pesquisas e desenvolvimentos aproximam conhecimentos, tecnologias e inovações desenhadas, inicialmente, para os carros e caminhões. Essa apropriação envolve uma acumulação de conhecimento e posterior tratamento dessas informações para o emprego em tratores com rodas. Além dessas atualizações, os entrevistados das empresas $\mathrm{E}_{4}$ e $\mathrm{E}_{5}$ sinalizaram que os seus departamentos trabalham em projetos próprios, mas de caráter sigiloso.

Um elemento importante para a análise dos esforços inovativos é o relacionamento com os fornecedores. A própria montadora estimula os seus fornecedores a desenvolverem processos de inovação, pois os mecanismos utilizados na transação induzem o fornecedor a prestar um serviço de qualidade, a qual pode ser mensurada com base na redução dos custos das peças, pela qualidade do produto, pela rapidez na entrega, entre outros elementos. O fato é que o sistema de qualidade estabelecido induz um movimento de atualização das 
peças e componentes. O relacionamento, regrado por contratos em que a qualidade é exigida, induz o avanço tecnológico de ambas as partes, que se tornam exigentes, aproximando a realidade observada com os escritos de Lundvall (2004). Isso quer dizer que as incertezas quanto à continuidade das transações regra os comportamentos, tornando-os mais rápidos para responder a uma mudança tecnológica. Após entrarem em uma trajetória tecnológica, as empresas criam um impulso próprio, direcionando as atividades, que se tornam rotineiras. A Figura 3, a seguir, demonstra, em resumo, os esforços inovativos realizados pelas empresas.

Figura 3: Esforços inovativos e rotinas empreendidas por empresas fabricantes de máquinas e equipamentos agrícolas no Brasil, 2015.

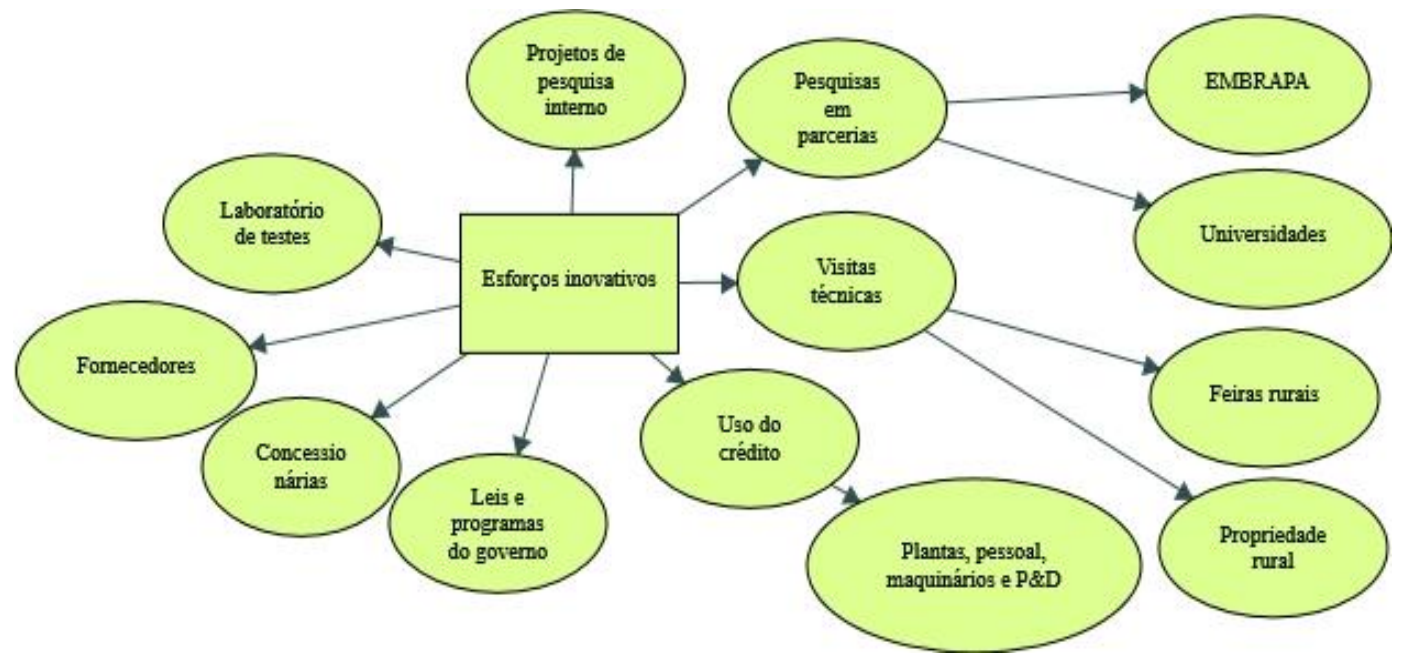

Fonte: Elaborada pelo autor, com base nos dados primários da pesquisa.

A partir da análise de conteúdo, foi possível identificar quatro recursos capazes de influenciar, diretamente, a capacidade de aproveitamento das oportunidades das empresas no setor. O primeiro recurso, e fortemente destacado, foi o capital que em momentos de crise, mesmo sabendo da oportunidade de inovar, foi difícil alocar recursos e disponibilizar um ambiente propício para o exercício da inovação. O segundo recurso destacado foi o tecnológico, pois os entrevistados entendem que, por mais que existam centros de pesquisa e desenvolvimento interno, muitas inovações surgem de outros setores da economia, tais como física, química, engenharias, metalomecânico, entre outros. O terceiro recurso com mais incidência nas entrevistas foi o de máquinas e equipamentos das próprias fábricas. Os entrevistados argumentam que muitos equipamentos não são brasileiros e, com isso, há uma forte dependência de novos lançamentos, capazes 
de alavancar a produção. Isso também não quer dizer que as inovações internas não aconteçam, elas acontecem, sim, mas o grande potencial de mudanças ainda se concentra no lançamento dessas máquinas modernas. E, por fim, o quarto recurso ressaltado foi o humano, sendo ele o responsável por interpretar e utilizar todos os incentivos do setor, embora para ocorrer um bom aproveitamento, o indivíduo precisa estar com boas condições de trabalho, com bom conhecimento, boa estrutura produtiva, entre outros fatores capazes de mobilizar a força de trabalho.

\section{3 estratégias empresariais voltadas para a inovação}

Para a teoria neo-schumpeteriana, as estratégias empresariais, voltadas para a inovação dos tratores, caminham com a observação das ações tomadas ao longo dos anos, conforme a mudança tecnológica ocorria no ambiente. Dessa forma, para compor essa análise, é preciso considerar, com base nos dados apresentados, que as empresas analisadas possuem habilidades, experiências, competências, entre outros elementos que contribuem com o aproveitamento dos avanços, bem como com o processo de mudança em seus contextos produtivos. Baseando-se nisso, observou-se que as empresas têm aproveitado esse fato para avançarem com as proposições de mudanças, principalmente aquelas ligadas às novas técnicas e tecnologias do setor de máquinas e equipamentos agrícolas.

O posicionamento estratégico das empresas torna-se homogêneo ao longo dos anos, isto é, na medida em que o mercado não se apropria de uma tecnologia revolucionária, as poucas empresas existentes no mercado brasileiro tendem a seguir os mesmos caminhos para desenvolver os seus produtos, diferenciando-se em quesitos de apropriação e uso dos conhecimentos conquistados em sua trajetória. Assim, dadas as condições econômicas do ambiente, as empresas posicionam-se de determinada forma. Considerando a utilização do conhecimento pelas empresas, observou-se a existência de quatro ramificações estratégicas, que geram impactos nas organizações: estratégias para o setor (fusões, barreiras de mobilidade, localização do negócio, parcerias e benchmarking); aproveitamento de políticas públicas; criação de um plano de ação; e montagem de uma estrutura de inovação.

Estratégias para o setor: A primeira estratégia identificada na análise diz respeito às fusões que ocorreram no setor, desde a abertura das operações, no Brasil. Dessa forma, com base no relatório histórico da ANFAVEA (2013b; 2015) e do estudo de Castilhos et al (2013), foi possível identificar, entre 1965 e 2015, 27 fusões e aquisições no setor de máquinas e equipamentos agrícolas no Brasil. Levando como base o relato de experiência do entrevistado $\mathrm{E}_{3} \mathrm{~F}$, entende-se que "[...] as mudanças no ramo acontecem muito rápido, todo mundo precisa ficar ligado, se não, a fila anda [...] eu vi várias firmas boas fechar as portas". Por esse 
depoimento, entende-se que "fechar as portas" significa a finalização das operações de uma empresa, mas, ao alinhar as informações com os dados coletados do setor, é possível identificar que essas firmas, talvez, tenham sido compradas por outras empresas do próprio setor, tornando a "função" da estrutura do mercado mais complexa e robusta para competir. Nos termos de Dosi (2006), esse é um processo de movimento da estrutura de mercado, em que há uma substituição de produtos antigos por outros novos ou aperfeiçoados.

Como consequência dessas fusões, as empresas operam em grandes estruturas produtivas, com máquinas e equipamentos de última geração, empregam profissionais formados em todos os níveis (técnicos, tecnólogos, graduados e pós-graduados) e atuam em um mercado caracterizado como oligopólio. Essas características adotadas pelas empresas fazem surgir uma barreira de entrada, que dificulta os novos entrantes de participarem do setor como fabricantes de tratores médios com rodas, considerando os custos e as limitações técnicas. Devem-se considerar, também, as estratégias de posicionamento das fabricantes, pois a localização do negócio também interfere no bom andamento das operações.

De acordo com os entrevistados, no momento da implantação de uma nova unidade fabril, é preciso considerar a proximidade espacial entre a fábrica e os seus principais compradores, além da afinidade que a fábrica terá com os seus fornecedores, o município, e estado, etc. Sabe-se, ainda, que as empresas também recebem propostas de incentivos locais, tais como terrenos para a instalação da fábrica, incentivos fiscais proporcionados pelo Estado, benefícios por estarem próximos de universidades e demais centros de pesquisa. A proximidade com os fornecedores também é importante para a estratégia de seleção e manutenção de um fornecedor. Isso acontece em função das relações diárias que ocorrem para a execução do contrato. Dessa forma, as fabricantes buscam vantagens estratégicas em contratos com os fornecedores, já que, assim, podem reduzir custos de transporte, estoques, etc. A capacidade de aproveitar os benefícios dessas proximidades, assim como outras oportunidades, foi categorizada como um movimento estratégico, por tratar-se de um alinhamento entre o que se possui internamente, com as demais possibilidades de mudanças presentes no mundo. Uma das formas de operacionalizar essa estratégia nas fábricas foi realizar parcerias com as entidades que promovem avanços tecnológicos, tais como as universidades e demais empresas dos grupos econômicos de que participam.

Esse processo de leitura do ambiente tecnológico e posterior ação interna foi identificado como um processo estratégico de benchmarking. Trata-se de um processo de autoavaliação em relação às demais empresas. As empresas de máquinas e equipamentos agrícolas estão próximas de outros setores, como é o caso do setor automobilístico que nesses processos de avaliação acharam por bem 
implantar o processo de testes que já realizavam nos carros antes de lançarem o produto no mercado consumidor. Além dos testes de resistência, o funcionário $\mathrm{E}_{4} \mathrm{~F}_{2}$, em sua entrevista, também sintetizou uma ideia que gerou muitas atualizações na fábrica. Nas palavras do entrevistado, a ideia do benchmarking está sendo utilizada com a proposição de "aproveitar o conhecimento adquirido por outras unidades fabris para trazer benefícios".

Aproveitamento de políticas públicas: De forma geral, os entrevistados sinalizaram uma grande mudança a partir dos anos 9o, período que coincide com a abertura comercial do Brasil e a mudança nas formas de incentivos do governo, induzindo as empresas a incrementarem tecnologias praticadas por países desenvolvidos, como os países citados: EUA e França. Conforme salientado, anteriormente, os programas de incentivos passaram por modificações nas últimas duas décadas para buscar maior competitividade por meio da inovação. Esse fato ficou claro em documentos institucionais como a Política Industrial e de Comércio Exterior (PICE - 1993), o Plano Plurianual (1996), a Nova Política Industrial (1998) e a Lei de Inovação Tecnológica (Lei Federal n. 10. 973, de 02/12/2004). Esses textos, cada um induzindo um determinado comportamento social e econômico, trabalham com uma perspectiva de desenvolvimento em comum, ou seja, a de que, para conseguir competir, as empresas necessitavam aproximar a tecnologia e o conhecimento na proposição de inovações.

Além das observações e dos aproveitamentos internos dessas possibilidades, as empresas também estão associadas à ANFAVEA que, em nome das fabricantes, atua junto ao governo para fazer avançar o alinhamento de interesses. Trata-se de um movimento estratégico, no qual o governo induz a saída da zona estacionária e os demais agentes seguem o fluxo das inovações tecnológicas. As empresas E1, E3, $\mathrm{E}_{4}$ e $\mathrm{E}_{5}$, por meio dos seus representantes, sinalizaram que estão atentas aos editais, planos de governo, regimes de incentivos e demais políticas públicas. Sem exceção, os relatos informaram que todas as empresas estão conectadas com essas alterações e apostas para eventuais mudanças, pois o governo, por meio dos seus créditos subsidiados, incentivos fiscais, etc., tem a capacidade de induzir alterações de produtos, processos e distribuição pelo país. Vale salientar que, assim como Nelson e Winter (2005) sinalizaram, esse movimento das condições não está completo, pois, dependendo das condições técnicas, econômicas e sociais, novas combinações podem se formar nas montadoras, e elas estão cientes dessas condições de trabalho.

Planos de ação: De forma estratégica, as empresas costumam criar planos de ação para atuarem no setor econômico. Esses planos diferenciam-se em sua capacidade analítica, robustez, no envolvimento de agentes, entre outros elementos típicos de cada empresa. No entanto, alguns procedimentos podem ser generalizados, conforme foram identificados em todas as empresas entrevistadas. 
Ou seja, a forma pela qual observam os movimentos tecnológicos se alinham com os seus esforços inovativos e, consequentemente, com as estratégias criadas individualmente. Percebe-se que as competências requeridas pelas instituições, ao longo dos anos, evoluíram paralelamente ao desenvolvimento dos tratores. De acordo com os entrevistados, os processos que compõem a produção dos tratores no Brasil são complexos e exigem conhecimentos acerca do produto, como conhecimento de fabricação mecânica, de gestão, de tecnologias, entre outros.

Nesse sentido, as empresas preparam-se para fornecer e contribuir com o desenvolvimento dos tratores internamente. A entrevista $\mathrm{E}_{5} \mathrm{~F}_{3}$ explica como isso acontece na empresa em que trabalha: "dependendo da situação, nós estudamos métodos de pesquisas de mercado, quantitativo, qualitativo, de uma maneira bastante estruturada [...] além das nossas próprias pesquisas aqui". Com base no resultado desses levantamentos iniciais, as empresas trabalham, de acordo com o seu regime tecnológico, em suas competências, habilidades e conhecimentos. Essas estruturas organizacionais, mencionadas pela entrevista $\mathrm{E}_{5} \mathrm{~F}_{3}$, dizem respeito à forma como a empresa se organiza para lidar com as mudanças tecnológicas. Nesse sentido, a empresa cria uma estrutura capaz de suportar novas informações, que servirão de base para a tomada de decisão estratégica acerca das atualizações dos tratores. Para Nelson e Winter (2005), esse processo de mudança também pode ocorrer nas estruturas organizacionais, ao passo que as novas realidades são criadas e reformuladas no processo de desenvolvimento das competências. A partir desse desenvolvimento, as mudanças podem ser requeridas no emprego de novas máquinas, de novas técnicas, de novas tecnologias e até mesmo de um novo produto.

Estrutura de inovação: Percebe-se que a estrutura organizacional criada internamente pode ser utilizada como um recurso estratégico para promover a inovação. Como consequência, os ambientes tecnológicos internos das empresas diferenciam-se em suas tecnologias aplicadas, nos conhecimentos acumulados, tipos de parcerias efetuadas, modelos de tratores com que trabalham, apropriação de aprendizados de outros setores, entre outros quesitos que atenuam a diferenciação desses ambientes. Observa-se que, para melhorar esse ambiente tecnológico, as empresas têm buscado investir em P\&D e efetuar estratégias que induzam atividades inovativas internas, capacitando os tratores para as novas realidades do setor. Há, portanto, um alinhamento com a percepção de Freeman (1982), que dizia que as decisões estratégicas, voltadas para a tecnologia, possuem um caráter interdependente, em função do relacionamento que mantêm com outros sistemas produtivos. 
Figura 4: Estratégias empresariais indutoras da inovação tecnológica no setor de máquinas e equipamentos no Brasil, 2015.

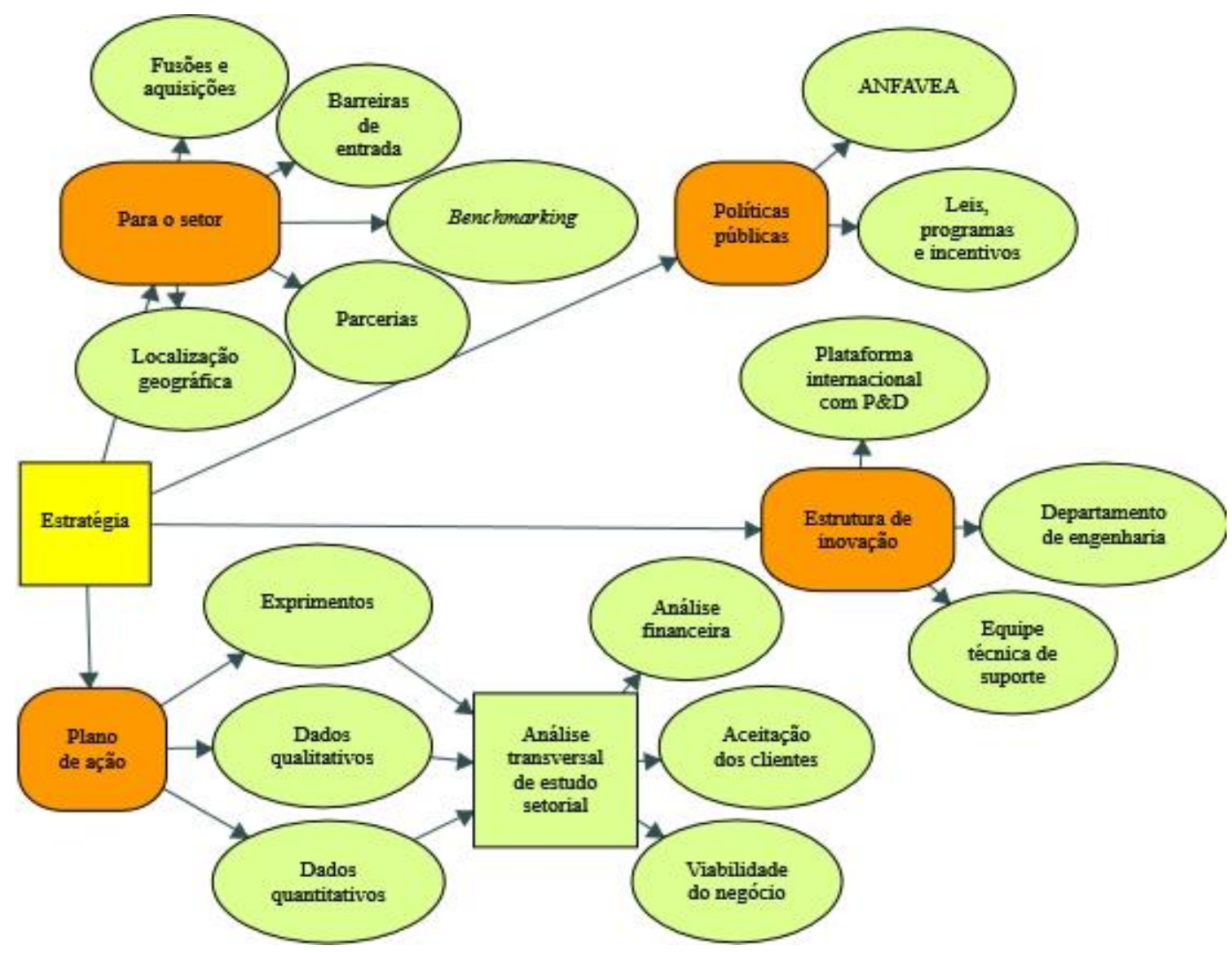

Fonte: Elaborada pelo autor, com base nos dados primários da pesquisa.

Para conseguirem disponibilizar equipamentos adaptáveis ao uso dos clientes, as empresas desenvolveram estruturas internas para suportar a procura por mudanças técnicas e tecnológicas no setor. As empresas implantaram, nas próprias estruturas, centros de inovações tecnológicas para sedimentar a rotina de melhorar continuamente. Óbvio que as estruturas encontradas variam de empresa para empresa, contudo é possível caracterizar alguns departamentos, bem como as empresas que os possuem, como: Plataforma internacional com P\&D (empresas E1, E2, E4 e E5), departamento de engenharia (todas as empresas) e equipes técnicas de suporte (todas as empresas). As inovações geradas nesses departamentos específicos são utilizadas pelas próprias empresas, fortalecendo um paradigma tecnológico que prioriza a solução de problemas por meio de um conjunto de informações técnicas e tecnológicas no campo. Isso implica pressupor que a 
própria atividade econômica produz e compartilha o aprendizado gerado com o auxílio de rotinas. A própria empresa estimula a captação de informações no ambiente externo e interno para propor mudanças em seus produtos e serviços.

A Figura 4, demonstra o agrupamento das principais estratégias já citadas. Vale salientar que os fornecedores contratados pelas empresas fabricantes também realizam pesquisas e inovações para elas. Esses fornecedores possuem estruturas empresariais bastante desenvolvidas, haja vista a grande quantidade de peças fornecidas para as fabricantes. Como um dos elementos analisados na contratação de um fornecedor é a capacidade tecnológica dele, as empresas fornecedoras acabam desenvolvendo projetos de melhorias, contribuindo com a evolução dos tratores.

De acordo com os entrevistados, muitas são as formas de se manterem atualizados no mercado de trabalho em que atuam. Dentre as principais ferramentas de "atualização" citadas estão: treinamentos internos, treinamentos externos, workshops, feiras de agronegócio, seminários de pesquisa, análise interna dos dados de produção, pesquisas realizadas na própria empresa, entre outras fontes de informação. Ao participarem desses meios, os profissionais, além de terem acesso às tecnologias de ponta, que estão sendo desenvolvidas nos centros de pesquisas, também podem discutir possibilidades de melhorias internas, em que as novas informações possam contribuir com a solução dos problemas reais da empresa.

\section{Considerações gerais acerca da perspectiva inovativa}

O objetivo proposto para o presente trabalho (compreender como as empresas, pertencentes à indústria de máquinas e equipamentos agrícolas no Brasil, respondem aos estímulos que a dinâmica inovativa exerce na conformação da trajetória tecnológica) foi cumprido. Com base na perspectiva teórica neoschumpeteriana, percebeu-se que as empresas estão se apropriando de tecnologias do setor como um todo e, para realizar esse processamento, elas amparam-se em três grandes aspectos que favorecem o desenvolvimento das trajetórias tecnológicas dos tratores médios com rodas.

O primeiro ponto destacado é o processo de aprendizado e conhecimento que, de acordo com as análises, demonstrou ser um ponto credível de avanços inovativos, mas também demonstrou ser uma ferramenta importante no processo de desenvolvimento, pois ao mesmo tempo em que executam as ações do dia a dia, também permite acumular conhecimentos para serem utilizados posteriormente, nas atualizações dos tratores, em termos de design do produto, sua força, produtividade e usabilidade no campo. 
O segundo ponto, categorizado como esforços inovativos e rotinas das empresas, também foi relevante para interpretar o comportamento dos agentes. Foi possível perceber que as empresas arquitetaram estruturas internas para produzir, apresentando um comportamento inovativo frente às mudanças agrícolas. As empresas analisadas, exceto a E2, apresentaram comportamentos inovativos, com departamentos muito próximos do que Pavitt (1984) sinalizou como fatores relevantes para se desenvolver intensidade tecnológica, porém, com a atual configuração dos registros de ideias e produtos (patentes), as adaptações brasileiras não são suficientes para mudar, de forma radical, o cenário mundial de tratores. Isso não minimiza a importância dos trabalhos desempenhados internamente, haja vista a grande diversidade de terrenos, climas e condições de trabalho para adaptar os tratores ao território brasileiro.

O terceiro ponto categorizado são as estratégias empresariais para inovação. Essas estratégias foram observadas do ponto de vista de posicionamento dos agentes no mercado, pois, na medida em que as inovações tomam dimensão, as empresas mobilizam-se para executar esse movimento internamente, produzindo e comercializando esses produtos no mercado. Como complemento às estratégias, a presença dos fornecedores também estimula as buscas, a seleção e a criação de rotinas das montadoras. Dessa forma, as empresas envolvidas diretamente com a produção do trator médio com rodas têm desenvolvido formas de responder aos novos problemas e limites que encontram no setor de máquinas e equipamentos. Os próprios sistemas de busca e de rotinas induzem o comportamento inovativo dos envolvidos, contribuindo com um regime tecnológico propenso a inovar.

Assim, no que diz respeito às próprias trajetórias tecnológicas dos tratores agrícolas, percebe-se que, ao longo dos anos, os tratores passaram por intensas modificações técnicas e conceituais, apropriando-se de tecnologias novas e existentes, ainda, influenciando a forma de trabalho dos produtores rurais. Esse resultado sinaliza que as empresas continuam aperfeiçoando o uso dos produtores rurais com a inserção de novas tecnologias para os tratores. Ao analisar as empresas e seus respectivos tratores com rodas, observa-se que as inovações realizadas em solo brasileiro tendem a ser de cunho adaptativo, modelando as tecnologias às necessidades dos produtores rurais. Cada empresa avança em um padrão de desenvolvimento, algumas canalizando forças para o aprendizado, outras para centros de P\&D, e isso as diferencia na hora de inovar e constituir sua trajetória tecnológica.

No que diz respeito às limitações do trabalho, entende-se que, por se tratar de uma indústria altamente concentrada e com a presença de grandes fornecedores, a pesquisa limitou-se com entrevistas com as fabricantes de tratores médios com rodas. A exploração do tema torna possível a execução de novos trabalhos, envolvendo as trajetórias tecnológicas com base no incremento de 
aspectos culturais, regionais, evolucionistas, pessoais, tecnológicos, entre outros pontos. Isso possibilitará o avanço das abordagens complementares na área e propiciará uma compreensão maior dos fenômenos organizacionais.

Contudo, este trabalho evidencia que a trajetória tecnológica dos tratores é influenciada por aspectos internos e externos da firma, cabendo às organizações interpretar as informações do ambiente institucional e tecnológico para atualizarem os seus próprios produtos e serviços. Parte desse movimento de adaptação ocorre devido à própria característica da tecnologia que, por vezes, avança em diferentes padrões, velocidades e ambientes. Com isso, as empresas do setor de máquinas e equipamentos agrícolas do Brasil desenvolvem suas estruturas internas, capacitam seu pessoal e ampliam os relacionamentos externos para compor um ambiente propício, condizente com a inovação tecnológica que irá desenvolver a trajetória tecnológica de seus tratores.

Referências bibliográficas

ANFAVEA - ASSOCIAÇÃO NACIONAL DOS FABRICANTES DE VEÍCULOS AUTOMOTRIZES. Carta da ANFAVEA (2013). Publicação mensal. N. 328, setembro, 2013b.

ANFAVEA - ASSOCIAÇÃO NACIONAL DOS FABRICANTES DE VEÍCULOS AUTOMOTRIZES. Anuário da indústria automobilística brasileira 2015. São Paulo: ANFAVEA, 2015.

BAUER, M W.; GASKEL, G. Pesquisa qualitativa com texto, imagem e som: um manual prático. Rio de Janeiro: Vozes, 2008.

CASTELLACCI, F. Technological paradigms, regimes and trajectories: Manufacturing and service industries in a new taxonomy of sectoral patterns of innovation. Research Policy, v. 37, n. 6-7, p. 978-994, 2008. DOI: https://doi.org/10.1016/j.respol.2008.03.011

CASTILHOS, C.C.; JORNADA, M.I.H da; STERNBERG, S.S.W.; GUILARDI, R.C. A indústria de máquinas e implementos agrícolas no RS: notas sobre a configuração recente. Ensaios FEE, v. 29, n. 2, 2013.

DOSI, G. The nature of the innovative process. In: DOSI, G. et all (org). Technical change and economic theory. London: MERIT, 1988, p.221-238.

DOSI, G. Mudança técnica e Transformação Industrial. Campinas: Unicamp, 2006.

FREEMAN, C. The Economics of Industrial Innovation. 2. ed. Londres: Frances Pinter, 1982. 
FREEMAN, C.; PEREZ, C. Structural crisis of adjustment: business cycles and investment behaviour. In: DOSI, G.; FREEMAN, C.; NELSON, R.; SILVERBERG, G.; SOETE, L. (eds.). Technical change and economic theory. London: Pinter, p. 38-66, 1988.

FREEMAN, C.; SOETE. L. A Economia da Inovação Industrial. Campinas SP, cap.1o. Editora da Unicamp, 2008.

IPEA - INSTITUTO DE PESQUISA ECONÔMICA APLICADA. O Brasil em 4 décadas. TD n. 1.50o. Brasília, 2010.

LEMOS, C. Inovação da era do conhecimento. In: LASTRES, H. M. M.; ALBAGI, S. Informação e globalização na era do conhecimento. Rio de Janeiro, 1999.

LUNDVALL, Bengt-Ake. National Systems of Innovation: towards a theory of innovation and interactive learning. London: Pinter Publishers, 1992.

LUNDVALL, Bengt-Ake. Introduction to 'technological infrastructure and international competitiveness' by Christopher Freeman', Industrial and Corporate Change, v. 13, n. 3, p. 531-539, 2004. DOI: https://doi.org/10.1093/icc/dtho21

MALERBA, F. Learning by firms and incremental technical change. The Economic Journal, 1992. DOI: https://doi.org/10.2307/2234581

MALHOTRA, N. K. Pesquisa de Marketing: uma orientação aplicada. 3. ed. Porto. Alegre: Bookman, 2001.

MAPA - MINISTÉRIO DA AGRICULTURA, PECUÁRIA E ABASTECIMENTO. Estatística e dados básicos de economia agrícola. Disponível em <http://www.agricultura.gov.br>. Acesso em 15/03/2016 às 03:15. 2016.

MILAGRES, R. Rotinas: uma revisão teórica. Revista Brasileira de Inovação, Campinas (SP), 10 (1), p.161-196, 2011. DOI: https://doi.org/10.20396/rbi.v1oi1.8649013

NELSON, R; WINTER, S. Uma teoria evolucionária da mudança econômica. Unicamp, 2005 .

NONAKA, I.; TAKEUCHI, H. Criação de conhecimento na empresa. São Paulo: Campus, 1997.

ORSENIGO, L. Technological regimes, patterns of innovative activities and industrial dynamics. Cahiers d'economie et sociologie rurales, v. 37, p. 23-67, 1995. 
PAVITT, K. Sectors patterns of technical change: Toward a taxonomy and theory. Research Policy, 1984. DOI: https://doi.org/10.1016/0048-7333(84)90018-o

PENTLAND, B. T. et al. Dynamics of organizational routines: A generative model. Journal of Management Studies, v. 49, n. 8, p. 1484-1508, 2012. DOI: https://doi.org/10.1111/j.1467$\underline{6486.2012 .01064 . X}$

ROSENBERG, N. Por dentro da caixa preta: tecnologia e economia. Campinas: Unicamp, 2006.

TIGRE, P. B. Gestão da inovação: a economia da tecnologia no Brasil. São Paulo: Campus, 2006.

Recebido em 09.08.17

Aprovado em 06.04.18 